\title{
Ocena jakości złączy spawanych ze stali X6Cr17 i X5CrNi18-10 stosowanych w wymiennikach ciepła
}

\author{
Quality assesment of X6Cr17 and X5CrNi18-10 \\ steels welded joints used in heat exchanger
}

\section{Streszczenie}

Przemysłowe urządzenia grzewcze często stanowią spawaną konstrukcję stalową wykonaną z cienkościennych rur i blach ze stali nierdzewnych. W obudowie o kształcie bryły prostopadłościennej umieszczone są rury powietrzne (rys. 1). We wnętrzu obudowy znajduje się komora spalania gazu, a cała przestrzeń obudowy jest przedzielona grodziami ukierunkowującymi odpowiednio przepływ spalin. Z obudową łączą się też rurki do odprowadzenia kondensatu, rura kominowa, tunel palnika itp.

Główne połączenia spawane występujące w wymiennikach ciepła to złącza blach obudowy oraz połączenia rur powietrznych z blachą obudowy. Z uwagi na wymaganą szczelność są to spoiny ciągłe.

\section{Abstract}

Industrial heaters are often a welded steel construction made of thin-walled tubes and sheets of stainless steel. In the case of a rectangular-shaped blocks are placed air pipe (fig. 1). Inside the cabinet is a gas combustion chamber, and the whole of the enclosure is divided by bulkheads targetable properly exhaust flow. With housing combine a tube to drain condensate flue pipe tunnel burner, etc. Main welded joints occurring in heat exchangers are sheet joints housing and the air pipe joints with sheet metal casing. In view of the required tightness they are continuous weld. This paper presents the results of the quality of joints found in industrial and commercial heating.

\section{Wstęp}

Przemysłowe urządzenia grzewcze często stanowią spawaną konstrukcję stalową wykonaną z cienkościennych rur i blach ze stali nierdzewnych. W obudowie o kształcie bryły prostopadłościennej umieszczone są rury powietrzne (rys. 1). We wnętrzu obudowy znajduje się komora spalania gazu, a cała przestrzeń obudowy jest przedzielona grodziami ukierunkowującymi odpowiednio przepływ spalin. Z obudową łączą się też rurki do odprowadzenia kondensatu, rura kominowa, tunel palnika itp.

Prof. dr hab. inż. Andrzej Ambroziak, dr inż. Piotr Białucki, dr inż. Wiesław Derlukiewicz, dr inż. Artur Lange - Politechnika Wrocławska.

Główne połączenia spawane występujące w wymiennikach ciepła to złącza blach obudowy oraz połączenia rur powietrznych z blachą obudowy. Ze względu na wymaganą szczelność są to spoiny ciągłe.

W pracy przedstawiono wyniki analizy jakości złączy występujących w grzewczych urządzeniach przemysłowych.

\section{Materiały na wymienniki ciepła przemysłowych urządzeń grzewczych}

Z analizy warunków pracy wymienników ciepła w przemysłowych urządzeniach grzewczych wynika, że ich części składowe nie podlegają dużym obciążeniom siłami zewnętrznymi, a w obszarze komory 
Tablica I. Zawartość pierwiastków stopowych w badanych stalach nierdzewnych wg EN 10088-3 [1], \% mas.

Table I. The content of alloying elements in tested stainless steels acc with EN 10088-3 [1], \% mas.

\begin{tabular}{|c|c|c|c|c|c|c|c|c|c|}
\hline Stal & Numer & $\mathrm{C}$ & $\mathrm{Si}$ & $\mathrm{Mn}$ & $\mathrm{P}$ & $S$ & $\mathrm{~N}$ & $\mathrm{Cr}$ & $\mathrm{Ni}$ \\
\hline $\mathrm{X} 6 \mathrm{Cr} 17$ & 1.4016 & maks. 0,08 & maks. 1,00 & maks. 1,00 & maks. 0,040 & $\leq 0,030$ & - & $16,0 \div 18,0$ & - \\
\hline X5CrNi18-10 & 1.4301 & $\leq 0,07$ & $\leq 1,0$ & $\leq 2,0$ & maks. 0,045 & $\leq 0,030$ & $\leq 0,11$ & $17,5 \div 19,5$ & $8,0 \div 10,5$ \\
\hline
\end{tabular}

spalania gazu temperatura blach dochodzi do $800^{\circ} \mathrm{C}$, natomiast po stronie przeciwnej wymiennika temperatura blach wynosi ok. $60^{\circ} \mathrm{C}$. Z tych powodów żarowytrzymałość stali nie jest podstawowym kryterium wyboru materiałów na wymienniki ciepła i dlatego producenci tych urządzeń stosują najczęściej stale nierdzewne o lepszej spawalności niż odpowiednie stale żaroodporne.

W konstrukcji analizowanego modułu grzewczego wymiennika ciepła zastosowano dwa gatunki stali nierdzewnej, których skład chemiczny podano w tablicy I.

Na obudowę zastosowano blachy wykonane ze stali nierdzewnej ferrytycznej X6Cr17 (PN- EN 10088-3), natomiast rury wymiennika wykonano ze stali nierdzewnej austenitycznej X5CrNi18-10 (PN-EN 10088-3). Grubość blach i ścianki rur wynosiła $1,5 \mathrm{~mm}$.

Stale ferrytyczne o zawartości $17 \%$ chromu wykazują wysoką odporność na utlenianie w powietrzu do temperatury $850 \div 900^{\circ} \mathrm{C}$. Stale te maja generalnie gorsze właściwości mechaniczne w wysokich temperaturach ze względu na strukturę ferrytyczną niż stale austenityczne. Natomiast żaroodpornością dorównują, a w niektórych środowiskach przewyższają stale austenityczne [2].

Zebrane na podstawie danych doświadczalnych wyniki obserwacji długotrwałej pracy stali w wysokiej temperaturze $w$ warunkach utleniających przedstawiono w tablicy II.

Wybrane gatunki stali nierdzewnej spełniają wymagania do pracy w urządzeniach grzewczych.

Tablica II. Odporność wybranych gatunków stali nierdzewnej na utlenianie w wysokiej temperaturze [3]

Table II. Resistance selected grades of stainless steel to oxidation at high temperature [3]

\begin{tabular}{|c|c|c|c|}
\hline \multicolumn{2}{|c|}{ Gatunek stali } & \multicolumn{3}{|c|}{ Maksymalna temperatura pracy w powietrzu } \\
\hline EN & ANSI & Praca nieciągła, ${ }^{\circ} \mathrm{C}$ & Praca ciągła, ${ }^{\circ} \mathrm{C}$ \\
\hline 1.4016 & 430 & 870 & 815 \\
\hline 1.4301 & 304 & 870 & 925 \\
\hline
\end{tabular}

\section{Rodzaje złączy}

Moduł wymiennika, którego fragment przedstawiono na rysunku 1, stanowi spawaną konstrukcję stalową wykonaną z cienkościennych rur i blach ze stali nierdzewnych.

Blachy obudowy wymiennika łączone są doczołowo bez ukosowania i bez odstępu w rowku spawalniczym (rys. 2a) oraz spoinami pachwinowymi (rys. 2b).

Rury powietrzne ułożone $\mathrm{w}$ rzędach stykają się z blachą obudowy pod różnymi kątami. Środkowy rząd rurek ułożony jest prostopadle do blachy obudowy,

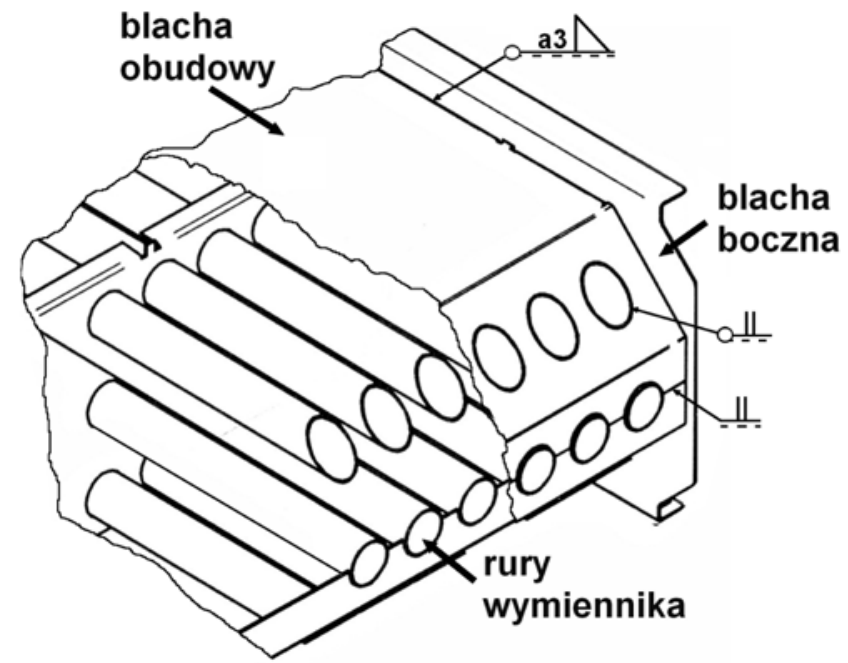

Rys. 1. Fragment modułu wymiennika ciepła

Fig. 1. A fragment of the heat exchanger module

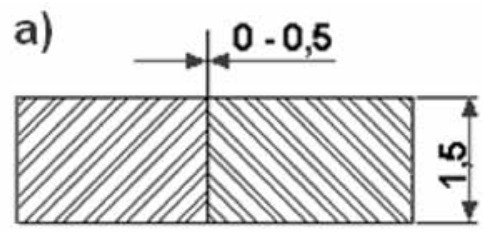

b)

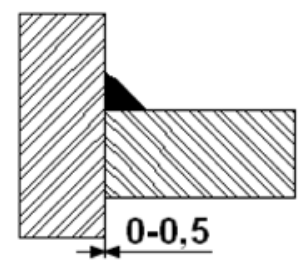

Rys. 2. Rodzaje złączy blach obudowy wymiennika: a) złącze doczołowe, b) złącze teowe

Fig. 2. Types joints cover plate heat exchanger: a) butt joint, b) T-shaped joint

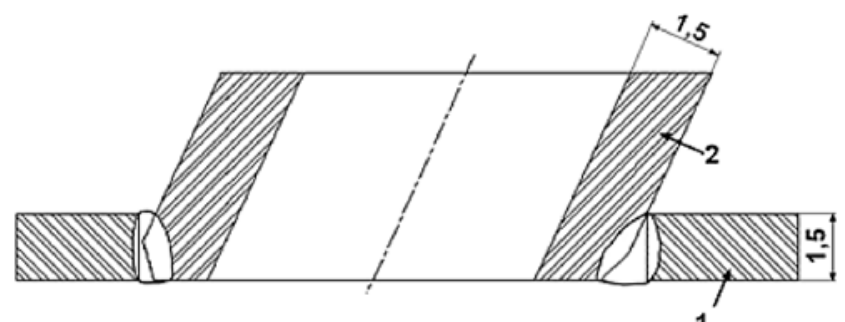

Rys. 3. Złącze rur powietrznych z blachą obudowy

Fig. 3. Air pipe joint with sheet metal casing

natomiast rurki $w$ rzędach zewnętrznych nachylone są do blachy obudowy pod określonym kątem i tworzą styk o zmiennym kształcie na obwodzie rury, przy czym spoiny można zakwalifikować jako spoiny czołowe $z$ jednostronnym ukosowaniem krawędzi rury i $z$ odstępem w rowku równym wielkości luzu między rurą i otworem w blasze, podobnie jak w przypadku rur ze środkowego rzędu (rys. 3).

Ukosowanie krawędzi rury ma nieregularny kształt, ponieważ powstaje w sposób przypadkowy podczas ogradowania krawędzi szlifowaniem ręcznym. Z uwagi jednak na małą grubość blachy, wynoszącą $1,5 \mathrm{~mm}$ 
wielkość ukosowania wynosząca $0,5 \div 1,0 \mathrm{~mm}$ może wpływać korzystnie na formowanie się spoiny, zwłaszcza na uzyskanie głębszego wtopienia w blachę złączy.

Dostęp do wszystkich wymienionych spoin jest łatwy i umożliwia ich poprawne wykonanie w dogodnej pozycji PA i PB. Wykonanie spoin pachwinowych łączących blachy obudowy oraz spoin czołowych rur z blachami obudowy wymaga przestawiana konstrukcji, ale ze względu na stosunkowo nieduży ciężar nie jest to trudne.

\section{Analiza metod spawania wymiennika}

W procesie produkcji modułu wymiennika stosowane są dwie metody spawania. Złącza doczołowe w obudowie oraz złącza rury z blachą obudowy wykonywane są ręcznie metodą TIG, natomiast ściany boczne obudowy wymiennika są spawane z obwodową częścią obudowy za pomocą półautomatycznej metody MGAW.

Metoda TIG w osłonie czystego argonu zapewnia precyzyjne spawanie cienkich blach i rur z maksymalnie możliwą kontrolą przetopu w spoinie. Nowoczesne urządzenia inwertorowe do spawania tą metodą pozwalają optymalnie sterować procesem spawania, co ma duży wpływ na jakość uzyskiwanych spoin.

Do spawania metodą MGAW stosowane są również nowoczesne urządzenia inwertorowe, które dzięki zaawansowanej konstrukcji stwarzają możliwość łatwego dopasowania parametrów spawania do optymalnych warunków procesu. W tej metodzie do osłony łuku stosowana jest mieszanka gazów zawierająca argon i ok. $2 \% \mathrm{CO}_{2}$.

\section{Materiały dodatkowe do spawania wymiennika ciepła}

W metodzie TIG przy spawaniu konstrukcji cienkościennych stosuje się wyłącznie czysty argon.

Osłona argonowa również w metodzie MIG jest bardzo skuteczna i umożliwia uzyskanie wysokiej czystości spoiny. Jednak kształt soczewkowy spoiny oraz napięcie powierzchniowe ciekłego metalu nie zawsze są wystarczające, aby uzyskać optymalny kształt spoiny. Dlatego przy spawaniu stali stopowych, także wielu stali nierdzewnych, zamiast metody MIG często stosuje się mieszanki gazowe z niewielkim dodatkiem $(1 \div 2 \%)$ gazu aktywnego $\mathrm{O}_{2}$ lub $\mathrm{CO}_{2}$, co uaktywnia tę mieszankę $\mathrm{i}$ dlatego właściwszą nazwą metody jest MGAW (Metal Gas Arc Welding). W metodzie MAG udział gazu utleniającego $\mathrm{w}$ mieszance $\mathrm{z}$ gazem obojętnym wynosi zwykle więcej niż $5 \%$.

Dodatek dwutlenku węgla sprzyja stabilnemu jarzeniu się łuku przy niskich parametrach prądowych, przy których metal drutu przechodzi do jeziorka w sposób zwarciowy mniej wrażliwy na przepalenia cienkościennych elementów.

Zastosowana stal ferrytyczna jest wrażliwa na przegrzanie, tzn. przy przekroczeniu temperatury $1000^{\circ} \mathrm{C}$ powstaje struktura gruboziarnista, co $\mathrm{w}$ połączeniu z wydzielaniem się węglików może prowadzić do jej kruchości $[4,5]$.

Zachowanie jednakowej odporności na korozję wymaga zastosowania spoiwa o zgodnym ze spawaną stalą składzie chemicznym. W przypadku stali ferrytycznej X6Cr17 (nr 1.4016, 430 wg ASTM) spoiwem takim jest np. spoiwo G17 wg EN 12072 (430 wg ASTM), dostępne głównie w metodzie GMAW. Jednak zastosowanie spoiw austenitycznych, np. 308LSi, 309LSi, 316LSi (tabl. III) w sposób istotny ułatwia spawanie, a jego wybór często dokonywany jest na podstawie wykresu fazowego Schaefflera (rys. 4) [5, 6].

Niemal dla każdego z wytypowanych spoiw, nawet przy założeniu min. $50 \%$ udziału spoiwa w materiale spoiny, skład chemiczny spoiny znajduje się w strefie dobrej spawalności (obszar wykresu zaczerniony).
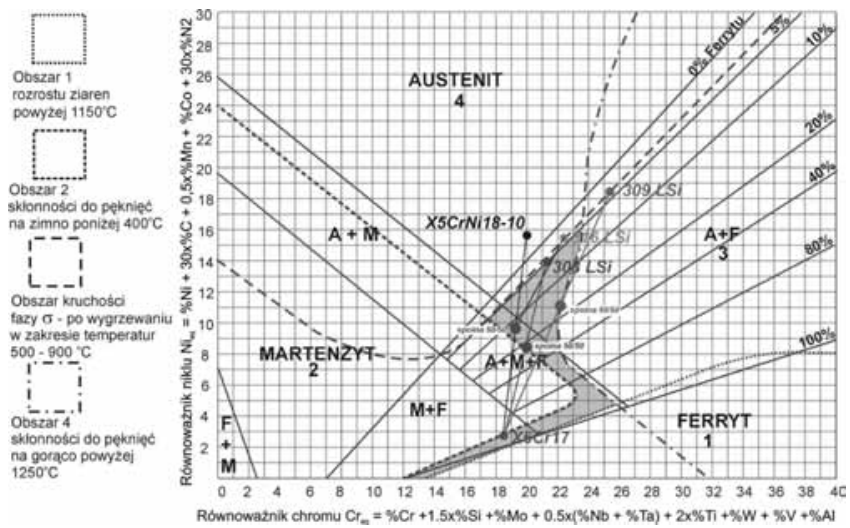

Rys. 4. Wykres Schaefflera z zaznaczonymi punktami odpowiadającymi spawanym stalom nierdzewnym, zastosowanym spoiwom oraz potencjalnym spoinom [5]

Fig. 4. Schaeffler diagram with marked points corresponding to weld stainless steels, applied filer metal and potential welds [5]

Tablica III. Zawartość pierwiastków stopowych w spoiwach austenitycznych, \% wag.

Table III. The content of alloying elements in austenitic filer metal, \% mas

\begin{tabular}{|c|c|c|c|c|c|c|c|c|c|}
\hline Spoiwo & $\mathrm{C}$ & $\mathrm{Si}$ & $\mathrm{Mn}$ & $\mathrm{P}$ & $\mathrm{S}$ & $\mathrm{Cr}$ & $\mathrm{Ni}$ & $\mathrm{Mo}$ & $\mathrm{N}$ \\
\hline 308LSi & $<0,025$ & 0,9 & 1,8 & $<0,025$ & $<0,015$ & 20 & 10,5 & $<0,3$ & $<0,06$ \\
\hline 309LSi & $<0,025$ & 0,9 & 1,8 & $<0,025$ & $<0,015$ & 23,5 & 13,5 & $<0,4$ & 0,10 \\
\hline 316LSi & $<0,025$ & 0,9 & 1,8 & $<0,025$ & $<0,015$ & 18,5 & 12 & 2,6 & $<0,060$ \\
\hline
\end{tabular}




\section{Wykonanie złączy próbnych}

Do badań wykonano w warunkach produkcyjnych złącza próbne doczołowe i teowe blach oraz kątowe rury $z$ blachą wg warunków podanych $w$ tablicy IV. Dla wykonanych złączy przeprowadzono badania wizualne zgodnie z PN-EN 970 oraz metalograficzne. Przykładowe złącza pokazano na rysunku 5.
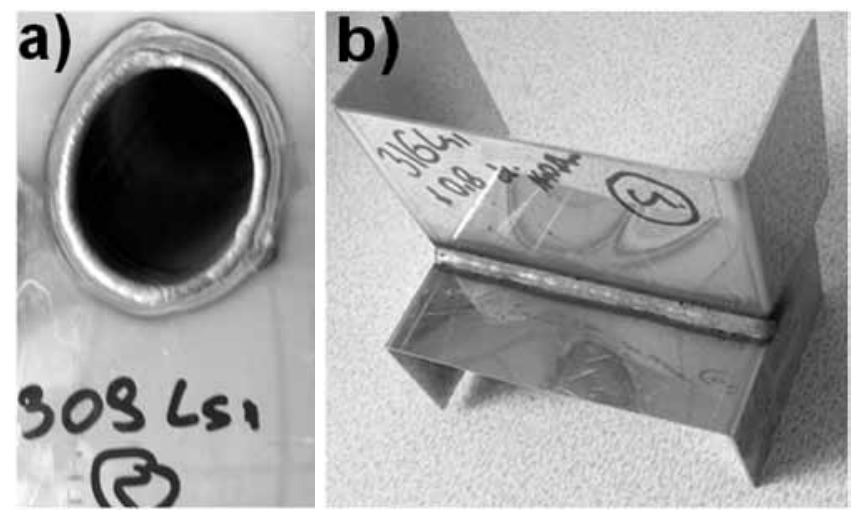

Rys. 5. Badane złącza: a) połączenie spawane rury wymiennika z blachą obudowy wykonane metodą TIG, b) złącze teowe między blachą obudowy i blachą boczną wykonane metodą GMAW

Fig. 5. View investigated joints; a) connection welded pipe heat exchanger with sheet metal casing made by TIG, b) T-shaped joint plate occurring between the housing and the side plate made by GMAW

\section{Badania wizualne i metalograficzne}

Przedstawione na rysunku 5a złącze ma układ łusek lica spoiny charakterystyczny dla spawania ręcznego metodą TIG, a jego szerokość wynosi ok. $4,5 \mathrm{~mm}$. Widoczne jest miejscowe poszerzenie nadlewu w miejscu zakończenia i rozpoczęcia nowych odcinków spoiny. Powierzchnia złącza od strony grani spoiny jest utleniona w sposób charakterystyczny przy braku osłony podczas spawania, której zastosowanie jest $w$ tym przypadku niemożliwe.

W złączu przedstawionym na rysunku $5 \mathrm{~b}$ lico spoiny jest gładkie, o równomiernej szerokości ok. $7 \mathrm{~mm}$ i lekko utlenionej powierzchni, charakterystyczne dla spawania ręcznego metodą GMAW.

$\mathrm{Na}$ powierzchni spoiny oraz na przyległych powierzchniach blach występują rozpryski metalu. Grubość spoiny wynosi $3,2 \div 3,5 \mathrm{~mm}$.

Obserwacje makroskopowe spoin wykonano z użyciem mikroskopu stereoskopowego OLYMPUS ZX7. Zgłady metalograficzne badanych złączy trawiono odczynnikiem Adlera. Dokonano też pomiarów

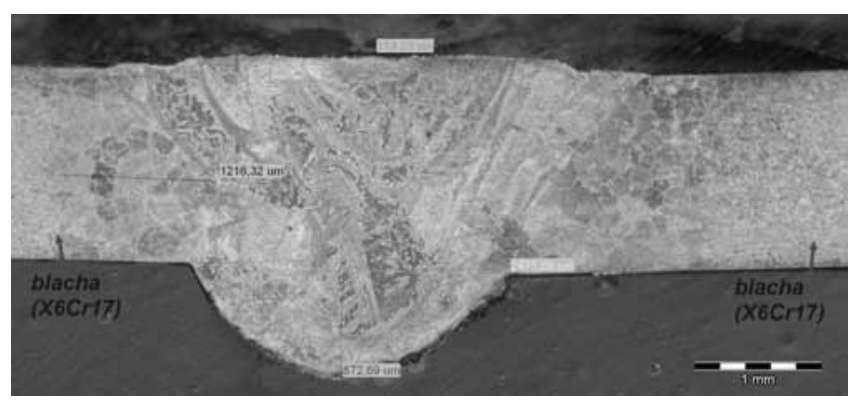

Rys. 6. Makrostruktura złącza doczołowego blach X6Cr17 spawanego metodą TIG. Trawiono odczynnikiem Adlera

Fig. 6. Macrostructure of butt joint of plate $\mathrm{X} 6 \mathrm{Cr} 17$ grade welded by TIG. Adler etching
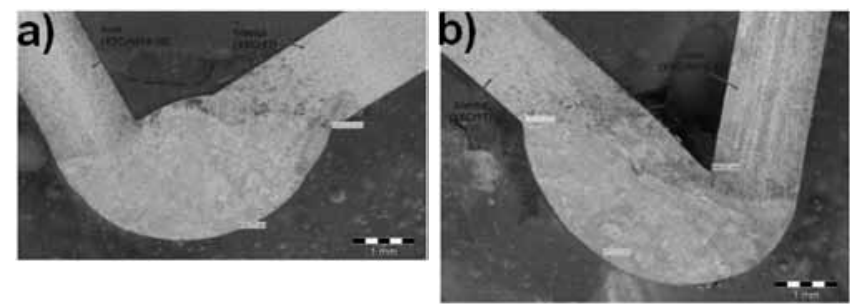

Rys. 7. Makrostruktura złącza doczołowego rury X5CrNi18-10 z blachą X6Cr17 spawanego metodą TIG. Trawiono odczynnikiem Adlera: a) przekrój spoiny w wybranym miejscu pełnego przetopu, b) przekrój spoiny w miejscu niepełnego przetopu

Fig. 7. Macrostructure of butt joint of pipe grade $\mathrm{X} 5 \mathrm{CrNi} 18-10$ with plate $\mathrm{X} 6 \mathrm{Cr} 17$ welded by TIG. Adler etching: a) cross-section of the weld at the desired location of full penetration, b) cross-section of the weld at the half-melting

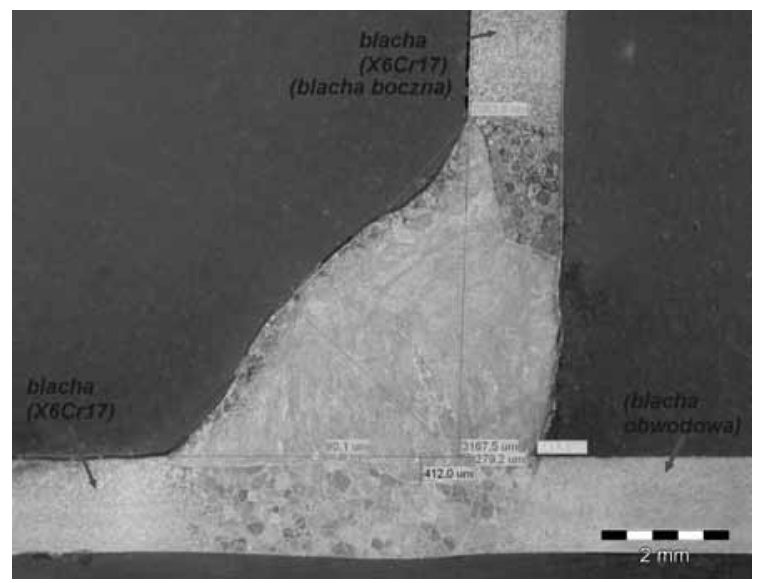

Rys. 8. Makrostruktura złącza teowego blach X6Cr17 spawanych metodą GMAW. Trawiono odczynnikiem Adlera

Fig. 8. Macrostructure of T-shaped joint of sheets $\mathrm{X} 6 \mathrm{Cr} 17$ grade weIded by GMAW. Adler etching

charakterystycznych wielkości elementów złączy spawanych. Przykładowe makrostruktury badanych złączy przedstawiono na rysunkach $6 \div 8$.

Tablica IV. Warunki wykonania złączy próbnych

Table IV. Working conditions of test joint

\begin{tabular}{|c|c|c|c|c|c|}
\hline Metoda spawania & Spoina & Materiał spawany & Spoiwo gat./śred. & Prąd, A & Uwagi \\
\hline TIG & czołowa & $\mathrm{X} 6 \mathrm{Cr} 17+\mathrm{X} 6 \mathrm{Cr} 17$ & 309 LSi ø1,6 mm & 70 & \multirow{2}{*}{$\begin{array}{l}\text { Spawanie łukiem pulsującym celem } \\
\text { uniknięcia przepalenia cienkich blach }\end{array}$} \\
\hline TIG & czołowa & $\mathrm{X} 6 \mathrm{Cr} 17+\mathrm{X} 5 \mathrm{CrNi18}-10$ & 309 LSi $\varnothing 1,6$ mm & 60 & \\
\hline GMAW & pachwinowa & $\mathrm{X} 6 \mathrm{Cr} 17+\mathrm{X} 6 \mathrm{Cr} 17$ & 316 LSi ø0,8 mm & 145 & Rozpryski (za małe napięcie) \\
\hline
\end{tabular}


Spoina czołowa, której makrostrukturę przedstawiono na rysunku 6 , jest zadowalającej jakości, a szerokość strefy SWC w tych złączach wynosi od 0,8 do $1,8 \mathrm{~mm}$. Różna szerokość tej strefy po obu stronach spoiny wynika $z$ kąta pochylenia elektrody względem rowka spawalniczego.

Trudniejszym zagadnieniem technologicznym jest złącze rury z blachą, gdyż rowek spawalniczy na obwodzie rury ma zmienne położenie i kąt nachylenia (rys. 3). Uzyskanie przetopu w tym przypadku jest trudne, lecz z punktu widzenia odporności na korozję bardzo wskazane (rys. $7 \mathrm{~b}$ ).

Na podstawie wyników przeprowadzonych badań mikrostruktury złączy spawanych można zauważyć, że stal ferrytyczna jest bardzo wrażliwa na rozrost ziaren w strefie wpływu ciepła mimo stosowania niskich parametrów spawania (rys. 9).

\section{Podsumowanie}

Przeprowadzone badania umożliwiły ocenę jakości złączy z uwzględnieniem warunków konstrukcyjnych i technologicznych występujących w urządzeniach grzewczych. Przyjęte parametry spawania złączy doczołowych metodą TIG należy uznać za poprawne, gdyż badane złącza spełniają wymagania najwyższego poziomu jakości $B$.

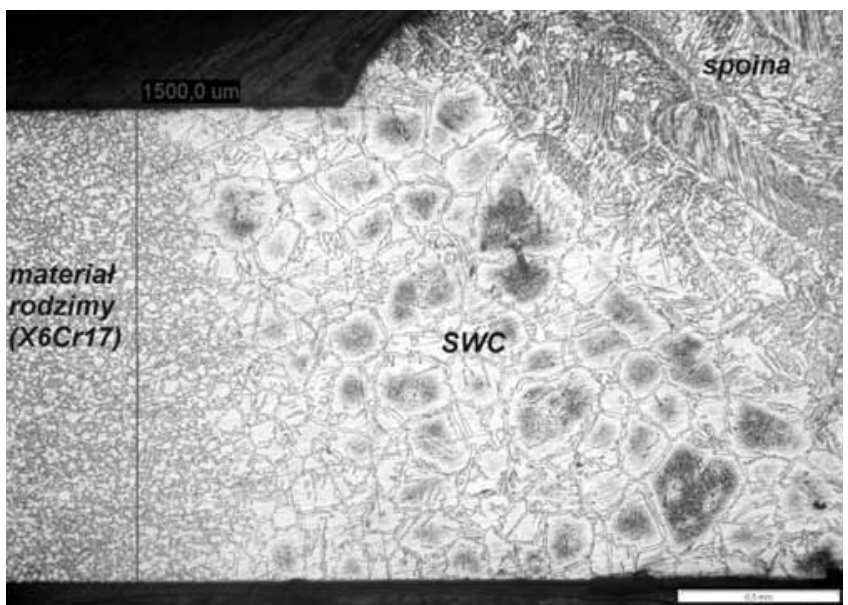

Rys. 9. Mikrofotografia doczołowego złącza spawanego blach X6Cr17 wykonanego metodą TIG. Trawiono elektrolitycznie. Pow. $50 \mathrm{x}$

Fig. 9. Microstructure of TIG butt welded joint made of sheets $\mathrm{X} 6 \mathrm{Cr} 17$ grade. Electrolytically etching. Magn. 50x
Spoiny czołowe w złączach rury z blachą obudowy zaleca się wykonywać z pełnym przetopem, dokonując korekty kształtu rowka spawalniczego, aby poprawić penetracje łuku na grubości blachy.

Zaleca się usuwanie rozprysków spawalniczych z powierzchni spoiny i blach przy spawaniu metodą GMAW oraz pasywację oczyszczonej powierzchni celem zwiększenia odporności na korozję.

\section{Literatura}

[1] PN-EN 10088-3:2007. Stale odporne na korozję - Część 3: Warunki techniczne dostawy półwyrobów, prętów, walcówki, drutu, kształtowników i wyrobów o powierzchni jasnej ze stali nierdzewnych ogólnego przeznaczenia.

[2] Wrobec S., Weber T.: Nowoczesne materiały żaroodporne. WNT, Warszawa 1982.

[3] WWW.investa.pl „Stal nierdzewna. Poradnik”. Opracowany przez firmę INVESTA. 2012-11-05.
[4] Dobrzański L.: Podstawy nauki o materiałach i metaloznawstwo. WNT, Warszawa 2006.

[5] Tasak E.: Spawalność stali konstrukcyjnych. Fotobit, 2002 r.

[6] Praca zbiorowa pod red. J. Pilarczyka: Poradnik Inżyniera. Spawalnictwo. T 1. WNT 2003. 